Miscelánea 



\title{
Acerca de la naturaleza jurídica del cadáver
}

\author{
Ronald Cárdenas Krenz \\ Universidad de Lima, Lima, Perú
}

Recibido: 30/7/2018 / Aprobado: 14/1/2019

doi: 10.26439/iusetpraxis2018.n48-49.4505

\begin{abstract}
Resumen. Se estudia la naturaleza jurídica del cadáver partiendo de que, con la muerte, el ser humano no se convierte en un mero objeto de derecho, toda vez que existen derechos que perviven más allá del fin de su existencia física. Se analiza, asimismo, la determinación del momento en que se produce la muerte (en el caso de las personas en estado vegetativo), así como las posibilidades e imposibilidades respecto al destino del cadáver (incluyendo diversas cuestiones vinculadas con los velorios, entierros y sepulturas). Finalmente, se hace una evaluación crítica de la consideración del cadáver como objeto del derecho de propiedad.
\end{abstract}

\footnotetext{
PALABRAS CLAVE: naturaleza del cadáver / derechos post mortem / tratamiento del fallecido / derecho a la sepultura
}

\begin{abstract}
About the legal status of a corpse
Авstract. This paper aims at studying the legal status of a corpse on the basis that, after death, human beings do not turn into a mere object of law because there are rights that endure beyond the end of a physical existence. Additionally, establishing the moment in which death occurs (in the case of people in vegetative state), as well as the possibilities and impossibilities of a corpse's destiny (including several issues such as wakes, burials and graves), is analyzed. Finally, a critical evaluation of the corpse considered as an object of proprietary law is conducted.
\end{abstract}

KEYWORDS: status of a corpse / post mortem rights / management of dead bodies / right of burial 


\section{INTRODUCCIÓN ${ }^{1}$}

Una lección que suele repetirse casi invariablemente en los cursos de derecho civil es que, con la muerte, la persona deja de ser sujeto de derecho y se convierte en objeto de derecho. Esto es así, según Lyon Puelma (2007), porque "la personalidad de los individuos humanos termina con la muerte de los mismos" (p. 50). Igualmente, Valencia Zea y Ortiz Monsalve (2004) ratifican que "con la muerte se extingue la personalidad del ser humano; por lo tanto, deja de ser sujeto de derechos" (p. 326). León Barandiarán (1980) concluye: “Cuando deja de existir el sujeto humano, desaparece toda posibilidad ontológica para que posea status jurídico alguno post mortem" (p. 91).

Sin embargo, vale la pena revisar la cuestión. Despojados de la vida, ¿podemos decir con propiedad que nos convertimos en simples objetos? En mayo del 2016, una noticia procedente de Estados Unidos concitó una gran inquietud: la empresa de biotecnología Bioquark acababa de obtener permiso para intentar "revivir" parte del cerebro de personas declaradas clínicamente muertas, para lo cual utilizaría pacientes de un hospital de la India, a través de un proyecto denominado muy expresivamente "Reanima". Ciertamente, la vida de una persona termina con su muerte, pero la historia de su cuerpo parece que no se acaba allí necesariamente. La historia nos cuenta, por ejemplo, los distintos destinos que tuvieron los restos de diversos personajes históricos:

- Cicerón: le cortaron la cabeza junto con sus manos; estas partes fueron enviadas a Antonio en Roma, quien dispuso que las colgaran en los estrados donde hablaban los oradores (Critchley, 2009, p. 117).

- Descartes: su itinerante vida, que le llevó a tener treinta y ocho domicilios, fue seguida de un destino itinerante que prosiguió después de muerto, pues fue enterrado en Suecia y, posteriormente, trasladado a París en un largo recorrido de once meses por varias ciudades. Luego de ser instalado en la iglesia de Sainte-Geneviève, pasó por otros dos cementerios hasta terminar en el antiguo monasterio de Saint-Germain-des-Prés (Critchley, 2009, p. 193). En

1 La presente investigación ha sido elaborada con el apoyo del Instituto de Investigación Científica de la Universidad de Lima (IDIC). Además, se contó con la valiosa colaboración de la alumna Sandra Rovegno Loayza, estudiante de la Facultad de Derecho de la misma casa de estudios. 
el ínterin, el embajador de Francia se quedó con su dedo índice derecho como recuerdo, porque quería conservar el dedo que había escrito "Cogito, ergo sum" (Doval, 2013, p. 97).

- Tomás Moro: luego de ser decapitado, su cabeza fue colocada en la punta de una lanza en el puente de Londres.

- Rasputín: en el año 2004, un museo de San Petersburgo hizo una exhibición de su miembro viril.

- Napoleón: en Estados Unidos, se encuentra preservado el miembro viril de Napoleón Bonaparte, el cual fuera adquirido nada menos que en una subasta.

- William Wallace: los restos del famoso héroe escocés - que encarnara en el cine Mel Gibson en la película Corazón valiente-, una vez ejecutado, fueron repartidos en diversas ciudades: un brazo fue a dar a Newcastle, otro a Berwick, una pierna a Perth y otra a Aberdeen. En cuanto a su cabeza, fue exhibida en el puente de Londres.

- Jeremías Bentham: fiel a su convicción utilitarista y atendiendo a su voluntad, terminó disecado y puesto a la vista del público en una urna de cristal del University College de Londres (se cuenta que, años después, un día se cayó y su cráneo terminó como balón de fútbol, motivo por el que ahora luce mejor guardado en otro ambiente más privado de dicha universidad).

- Osama bin Laden: de acuerdo con la versión oficial estadounidense, sus restos, en mayo del 2011, fueron tirados al mar, aunque posteriormente diversos medios como The New York Times han puesto en duda esta versión.

Claro que existen también otros destinos más dignos de un cadáver, como su aprovechamiento para la realización de trasplantes de órganos, la investigación científica, fines didácticos (escuelas de medicina), sociopolíticos ${ }^{2}$, como también culturales y hasta turísticos ${ }^{3}$.

A propósito de la consideración de los cadáveres, vale decir que ni ellos se han librado de la moda de los selfis. Se han reportado muchos

2 Se dice que el cuerpo de Lenin es la momia mejor conservada de la historia; además, su cerebro fue dividido en 20000 secciones para ser estudiado por el Instituto Cerebral Soviético (Doval, 2013, p. 102).

3 Piénsese, por ejemplo, en el Museo de las Momias de Guanajuato en México. 
casos en diferentes lugares del mundo, en los que médicos o enfermeras - con siniestro y perverso gusto - no han dudado en tomarse una foto al lado del difunto recientemente fallecido. Adicionalmente, si hablamos de tecnología, no puede obviarse mencionar la pretensión del uso del semen de un cadáver para engendrar un hijo póstumo, los pedidos de crioconservación de cerebros con fines de futuros trasplantes o para su "instalación" en computadoras, entre otras cuestiones polémicas.

Por todo ello, es importante revisar el tema de la naturaleza jurídica del cadáver, advirtiendo desde ya que, con la muerte, perdemos nuestra condición de seres humanos, pero seguimos hablando de restos humanos, no de cualquier cosa, pues nos referimos a alguien que fuera persona, cuya muerte trunca naturalmente su futuro, pero de ninguna manera puede borrar su pasado.

\section{CONSIDERACIONES GENERALES EN TORNO AL CADÁVER}

La definición del estatus jurídico del cadáver es fundamental para comprender el trato que merece. Más aún, si tenemos en cuenta algunas incongruencias del sistema jurídico que hacen que, en muchos países, tenga mayor sanción el robo del anillo de oro que lleva una mujer difunta que el tener relaciones sexuales con su cadáver.

El ser humano pierde su personalidad con el fallecimiento, no hay otra manera (Lete del Río, 1996, p. 53); "la muerte es la única causa de extinción de la personalidad civil" (Verdera, 2019, p. 20); no existe ya la antigua figura de la "muerte civil". Pero, sin perjuicio de ello, se debe tener presente que el cuerpo del fallecido merece respeto, misericordia, consideración, tanto por lo que es como por lo que fue, y por lo que significa para los suyos. No podemos considerarlo como un simple material de desecho que ha perdido su lugar en una sociedad de consumo. Como se ha dicho en la doctrina, al pasar la persona de la condición de "sujeto de derecho" a la de "objeto de derecho", ocurre esto:

Desaparece la persona en cuanto tal, con sus atributos y cualidades, cesando de ser centro de poder y de responsabilidad; se extinguen las relaciones y derechos personalísimos o vitalicios que le competían; y se abre la sucesión en los restantes, transformándose el patrimonio en herencia y el cuerpo de la persona en una cosa: el cadáver. (Lacruz Berdejo et al., 2010, p. 20) 
Empero, la cuestión del cambio de condición no es solo una digresión académica o una exquisitez jurídica, pues, por ejemplo, puede ser particularmente relevante para determinar la sanción aplicable a un delito, como en el caso del llamado "descuartizador de la maleta", ocurrido en Lima en julio del 2012. Los hechos fueron los siguientes: una persona es encontrada muerta, cortada en pedazos, dentro de una maleta; identificado el supuesto asesino, su abogado basa su estrategia de defensa en que si bien el acusado reconocía que descuartizó a la víctima, ella ya estaba muerta por causas naturales - un supuesto infarto- en el momento en que fue cortada en pedazos, por lo que no se le podía acusar de atentar contra la vida de quien ya no estaba vivo. El caso terminó en agosto del 2014 con la sentencia dictada por la Sala Penal Transitoria de la Corte Suprema, que ratificó la condena de 30 años de cárcel contra Ricardo Vásquez Mori por el asesinato de Enrique Armestar Ansi, sanción que fuera establecida en diciembre del 2013 por la Primera Sala Penal para Reos en Cárcel de la Corte Superior de Justicia de Lima. Se ordenó, asimismo, pagar 250000 soles por concepto de reparación civil. El Poder Judicial, por tanto, no acogió los argumentos de Vásquez, y determinó que Armestar todavía estaba con vida cuando empezó a ser descuartizado.

Desde un punto de vista estrictamente jurídico, quien descuartiza a una persona que ya está muerta, no comete asesinato. Tampoco podría cometer técnicamente ninguna violación quien realiza el acto sexual con un cadáver. Si bien autores como Verdera (2019) afirman que "tras la muerte, el cuerpo de la persona debe calificarse de cadáver, y este merece la consideración de cosa" (p. 221), discrepamos - vistos los casos mencionados - con que pueda decirse sin más que un cadáver es una cosa; en todo caso, parece más apropiado hablar de un objeto o un bien sui generis. Como dice Espinoza (2012):

El ser humano, durante su vida, es relación coexistencial con otros seres humanos, pero cuando esta relación se termina, culmina su finalidad como ente viviente (ser existencia y coexistencia a la vez), deja de ser sujeto de derecho para convertirse en un objeto de derecho sui generis, digno de ser protegido. (p. 975)

Tampoco puede verse el cadáver como una res nullius, pues no es una cosa de la que cabe apropiarse. Los muertos (como tampoco los vivos) no pertenecen a nadie. "Dicho objeto material se encuentra fuera del comercio, no tiene valor económico y no puede ser materia de derechos 
personales o reales, de tal manera que es revestido de cierto halo de sacralidad que lo excluye de operaciones mercantiles" (Morelli, 2009, p. 128). Cabe anotar que tal sacralidad no implica necesariamente un concepto religioso, pues también puede reconocérsele un carácter jurídico, como señala Cantor (2010):

La santidad de los restos humanos no era solo un precepto religioso, sino también un elemento de la ley y la costumbre. [Estas] aceptaban que un cadáver había sido una persona, todavía tenía un gran parecido con esa persona, constituía un símbolo tangible de la imagen/identidad de por vida de esa persona y, por lo tanto, merecía ser tratado con la dignidad "humana" apropiada, aunque ya no era una persona. Yo lo llamo el derecho a la "dignidad humana post mortem". (p. 43)

En resumidas cuentas, siguiendo a Vide (1998), puede decirse que se trata de "una cosa singular, cuasisagrada, trasunto de la dignidad de la persona que albergó y, en cuanto tal, fuera del tráfico ordinario" (p. 37). En todos los casos, es de recordar siempre que al cadáver, aunque ya no es un sujeto, se le debe respeto, piedad, misericordia, compasión, etcétera, pues no es cualquier objeto; es alguien que tuvo vida, alguien que fue un ser humano.

Vale decir que, en nuestra legislación, el artículo 22 del Decreto Supremo 014-88-SA (1988) estableció: "Por el hecho de la muerte, la persona, que en vida es sujeto de derecho, se convierte en un objeto especial digno de respeto y piedad $[\ldots]]^{\prime \prime}$. En esa línea de pensamiento, el reglamento de la ya derogada Ley 23415 (2004), modificado por la Ley 24703 (1987), establecía en su artículo 31: “La extracción de órganos de personas fallecidas se efectuará de modo de evitar mutilaciones o disecciones innecesarias. El cadáver debe ser recompuesto con el mayor esmero que la naturaleza exige". Como dice Kierkegaard: "A un muerto hay que tratarlo como se trata a un dormido, a quien uno no se atreve a despertar, porque se abriga la esperanza de que algún día despierte por sí mismo" (Llevadot, 2011, p. 117).

\section{SOBRe LA DETERMINACIÓN DEL MOMENTO EN EL QUE SE PRODUCE LA MUERTE}

Determinar desde qué momento se considera muerta a una persona es un asunto estrictamente médico o, más precisamente, científico. De allí que hagan bien los Códigos Civiles - como el del Perú o de Argentinaen evitar una definición, dejando librado el asunto al progreso científico 
y tecnológico, lo que parece ser prudente. Como señala Lorenzetti (2014): “La definición o conceptualización de la muerte es algo que atañe más bien a la tanatología, la biología o la medicina y las leyes especiales" (p. 401). Establecer la "hora cero", el momento preciso de la muerte, es un tema debatido y debatible que inevitablemente motiva problemas no solo legales y científicos, sino también éticos (AriasSchreiber Pezet, 1991, p. 67).

Empero, la pregunta no es nueva y a lo largo de los tiempos ha despertado inquietudes tanto metafísicas como físicas, vinculadas, entre otras cosas, a diversos temores. Así, un estudio parisino sobre últimas voluntades, luego de revisar mil testamentos realizados entre 1760 y 1777, concluyó que trece de ellos incluían salvaguardas para prevenir un entierro precipitado; el temor parecería ser fundado si tenemos en cuenta que, en 1749, el médico francés Jean-Jacques Bruhier había afirmado haber encontrado 56 casos de este tipo (Jódar, 2015, párrs. 1 y 2). Cantor (2010) refiere cómo en el siglo xix se daban casos de personas que enfrentaron autopsias por equivocación, personas que murieron por haber sido mal diagnosticadas y la creación de una serie de técnicas para prevenir los entierros prematuros, algunas no muy científicas que digamos, como echar agua hirviendo en la frente del fallecido, clavarle agujas en distintas partes del cuerpo, introducir un objeto afilado por la nariz del supuesto difunto, etcétera (pp. 13-14).

Modernamente, como señala Morales Godo (1997), "el desarrollo de las técnicas de reanimación $\mathrm{y}$, fundamentalmente, los trasplantes de órganos provenientes de cadáveres han motivado la revisión del momento en que debe determinarse jurídicamente la muerte" (pp. 20 y 94). Se ha advertido que, en Estados Unidos, existen médicos que vendrían aplicando criterios demasiado flexibles para considerar muerta a una persona y aprovechar sus órganos para cubrir la demanda de estos (Cantor, 2010, p. 24).

No se trata de la pérdida de la conciencia ni de que dejen de funcionar todas las células de la persona para que pueda considerársele muerta, sino del cese del funcionamiento del organismo en conjunto, independientemente de que algunas funciones vitales todavía sigan parcialmente activas, lo cual se da fundamentalmente con el fin de aprovechar los órganos del fallecido para trasplantes.

Una persona está muerta cuando a nivel biológico deja de ser un organismo, es decir, un conjunto integrado. No es necesario que deje de vivir 
cada célula individual del organismo, sino que cese el organismo como un todo, aunque permanezcan funciones vitales. Las razones que justifican este concepto son antes que todo de orden pragmático, porque no se puede confiar en el criterio de la desaparición de conciencia para certificar la muerte, en cuanto con ello se entraría en un terreno inconsistente, sobre el cual no se pueden construir certezas. En segunda instancia, como apoyo del concepto de muerte como cese del organismo en cuanto conjunto integrado, está la argumentación antropológica de la unidad fundamental del ser humano. En el hombre la dimensión física está indivisiblemente unida con la dimensión psíquica. El cuerpo atraviesa y sostiene toda actividad psíquica, así como el psiquismo impregna todo el cuerpo. (Aramini, 2007, pp. 307-308)

No obstante, vale señalar que el diagnóstico médico no siempre es preciso y existen algunos márgenes en los que puede haber duda, por lo que se debe ser muy cuidadoso con ello:

A una temperatura corporal de $20^{\circ} \mathrm{C}$, el organismo necesita solo el $15 \%$ del oxígeno que suele requerir; la cifra puede descender si sumamos una ingesta excesiva de barbitúricos, fármacos que influyen poderosamente en el sistema nervioso central y pueden conducirlo a una anestesia total. En tal estado extremo, solo se registran diez o menos latidos por minuto y apenas dos o tres respiraciones; es difícil detectar el pulso o la respiración. (Jódar, 2015, párr. 5)

Una definición tradicional conceptualiza a la muerte como el cese permanente del funcionamiento del organismo, lo que constituiría la muerte clínica, mientras que la muerte biológica sería el cese de la actividad de todas las células de los tejidos del cuerpo, que se da en forma gradual hasta su descomposición.

En todo caso, hoy en día, la determinación de la muerte de la persona mayoritariamente se considera producida con la muerte cerebral. Esta noción fue desarrollada - señala Andorno (2012, p. 159) - a partir de un trabajo de Mollaret y Goulon, del año 1959, y difundida sobre todo a partir del informe de un comité ad hoc de la Harvard Medical School en $1968^{4}$, que dio a conocer los criterios Harvard para el diagnóstico de la

4 Limongi Franca (1995), por su parte, distingue: muerte encefálica (es la del cerebro como un todo, que sobreviene desde el momento de la cesación del dinamismo del tronco cerebral), muerte cerebral (es la de todo el cerebro, que ocurre desde el momento de la cesación del dinamismo del tronco, pero también del córtex), muerte clínica (se produce cuando cesan todas las actividades, no solo cerebrales, sino 
muerte cerebral y estableció un protocolo para tal efecto. Anota Rodríguez Ramos (2002, pp. 353-354) que mientras la muerte orgánica puede retrasarse artificialmente, "la muerte cerebral se corresponde con un hecho cierto, natural, irreversible y no manipulable por el hombre. En buena lógica, la muerte cerebral queda fuera de toda suspicacia, puede datarse con precisión y es perfectamente acreditable" (Laureys, 2005, p. 907) 5 . Ello, por cierto, no significa que, a la par del desarrollo de la tecnología y la medicina, no podamos en el futuro tener mayores precisiones acerca del concepto. Sobre el tema, se pregunta y responde Laureys (2005):

¿Cuál es el futuro de la muerte? La mejora de las tecnologías para la reparación del cerebro y el soporte protésico para las funciones cerebrales (por ejemplo, células madre, neurogénesis, prótesis de computadora neuronal, suspensión criónica y reparación nanoneurológica) podría cambiar algún día nuestras ideas actuales de irreversibilidad y obligar a la medicina y a la sociedad a revisar una vez más su definición de la muerte. (p. 907)

Prácticamente, en forma unánime, en la mayoría de los Códigos o de los ordenamientos jurídicos de nuestra época, el criterio que define la muerte es exactamente el momento en que se ha producido una cesación irreversible de la actividad cerebral, capaz de limitar el resto de las funciones (Palmero, 2000, p. 36). Otra definición de la muerte cerebral (brain death) afirma que es una "pérdida irreversible de la capacidad del organismo para funcionar como un todo, que resulta de la pérdida permanente de su sistema crítico" (Laureys, 2005, p. 901). La determinación de la muerte basada en el cese de las funciones del tronco cerebral (que implica la pérdida de la conciencia y la capacidad cognitiva) es segura; "ella garantiza, cuando es confirmada, seriedad ética sobre las extracciones de órganos con fines de trasplante" (Aramini, 2007, pp. 316-317). "La muerte clínica se hace coincidir con la cesación de la función cerebral [...]. La muerte clínica es la cesación total e irreversible de cualquier actividad del sistema nervioso central" (Fernández Sessarego, 2007, p. 219). Para mayor precisión, siguiendo a Pérez Gallardo (2014), podemos decir:

también respiratorias y cardiovasculares, no obstante la persistencia de alguna vida residual en las llamadas funciones vegetativas), muerte definitiva (la que se da a partir del momento de la desintegración final de los residuos vegetativos) (p. 60-A).

5 En estos casos, el tronco encefálico cumple algunas de las funciones básicas que normalmente corresponden al cerebro. 
Como se ha sostenido en una importante Declaración de Neurólogos, publicada por la Pontificia Academia Scientiarum de la Ciudad del Vaticano en el 2008, el concepto de muerte cerebral no intenta sugerir que existe más de una forma de muerte. Más bien, esta terminología específica hace referencia a una condición especial, que, dentro de una secuencia de sucesos, constituye la muerte de una persona. Así pues, la muerte cerebral es el cese irreversible de toda actividad cerebral vital. (p. 19)

Vale señalar que el Tribunal Constitucional chileno, en sentencia del 13 de agosto de 1995, sobre la constitucionalidad de los artículos 7, 10 y 11 del Proyecto de Ley 19.451, expresa en su 15: "[...] se llega a la conclusión de que la abolición total e irreversible de todas las funciones encefálicas constituye la muerte, real, definitiva, unívoca e inequívoca del ser humano", y agrega que "la muerte cerebral es el criterio jurídicamente más acertado para fijar el final de la personalidad".

\section{El caso de las personas en estado vegetativo}

Es esencial destacar que, como reiteran López y Abellán (2009, p. 53), una persona en coma profundo o en estado vegetativo, aunque ha perdido en forma severa (no total ni completamente irreversible) sus funciones físicas y mentales, sin embargo, tiene trabajando el tronco encefálico, por lo que preserva "el funcionamiento de los centros circulatorios y respiratorios; ha perdido funciones importantes, pero su cuerpo humano sigue funcionando como un organismo integrado y, por tanto, no está muerta" (Laureys, 2005, p. 906). Como dice Gómez-Lobo (2015):

El término vegetativo puede llevar a que la gente piense en estos pacientes como vegetales $\mathrm{y}$, por tanto, no humanos; a fin de evitar esta terrible confusión, se ha propuesto una nueva denominación: falta de respuesta después del coma (PCU), que está libre de asociaciones desorientadoras. (p. 226)

En el caso de los niños anencefálicos, aun cuando su cerebro no está desarrollado ${ }^{6}$, igual tienen la condición humana y merecen la misma consideración que cualquier otro ser vivo. Respecto a los bebés anencefálicos como donantes de órganos, nos remitimos a Sgreccia (2009, p. 833).

6 En estos casos, el tronco encefálico cumple algunas de las funciones básicas que normalmente corresponden al cerebro. 


\section{Cuestiones con Relación al destino del cadáver}

En la guerra de Troya, Aquiles mata a Héctor luego de luchar contra él; amarra su cadáver a su carruaje y lo arrastra para humillarlo, con lo que afrenta, de paso, a todos los troyanos. Entrada la noche, Príamo, padre de Héctor y rey de Troya, se escabulle hasta el campamento de Aquiles para pedirle -dramáticamente, pues está nada menos que ante el asesino que acaba de matar a su hijo - que le permita llevarse el cadáver para rendirle los honores fúnebres que le correspondían. Aquiles acepta y hasta da una tregua por unos días para que Héctor pueda ser debidamente despedido. Ante ello, los griegos le reclamaron a Aquiles por no haber aprovechado la oportunidad para atacar a los troyanos, pero pudo más en el héroe griego el respeto a la costumbre y la consideración del hijo muerto. Se trata de una respetuosa concesión que hace el vencedor griego, un gesto digno en medio de la guerra. En la antigua Grecia, era una idea extendida que cuando alguien moría, tenía que ponerse al difunto una moneda en cada ojo, a efectos de que pueda tomarla el barquero - que, según la leyenda, habría de conducir al fallecido al más allá - para que lo lleve de buena gana a un buen destino.

Es claro que, a la hora de analizar el destino del cadáver, debe tenerse en cuenta la costumbre, la cultura y las creencias de un lugar. No obstante, una cuestión poco abordada es hasta qué punto puede una persona dejar ciertas disposiciones vinculadas con su cadáver y qué tanto deben ellas ser obligatoriamente atendidas. Pasemos a tratar la cuestión, de suyo interesante. En Estados Unidos, la dama texana Sandra West, antes de fallecer en 1977, pidió que la enterraran junto con su Ferrari azul, lo que se cumplió fielmente en la ciudad de Texas, una vez que un juez desestimara el pedido de un familiar para que el auto no sea enterrado.

César Vallejo, el vate peruano, yace enterrado en París. En numerosas oportunidades se ha planteado la posibilidad de traerlo de vuelta al Perú, por su significado literario, por ser el poeta peruano más reconocido, etcétera, pero lo cierto es que, por más insigne que sea el autor de Los heraldos negros, debe respetarse su voluntad de ser enterrado (y seguir estando enterrado) en la capital francesa. El deseo del poeta fue manifestado libremente al amparo del principio de autonomía de la voluntad.

Otro caso histórico es el del prócer argentino Manuel Belgrano, quien descansa en el Convento de Santo Domingo de Buenos Aires, y no en el Monumento a la Bandera, del cual fue creador. Como dice Morelli (2009), si bien sería más útil trasladar sus restos al lugar del monumento 
para que sean honrados, visitados y conocidos, es correcto respetar su voluntad, pues:

No respetar su última voluntad suena irrespetuoso frente a alguien que hizo tanto por el país. Tanto que se antepone esa voluntad al interés social presente en el traslado; cosa distinta probablemente sería que tuviere que demolerse el convento para una obra pública. (pp. 126-127)

Por otro lado, así como hay personas que desean adornar su tumba con figuras religiosas, hay también quienes quieren dar una última rienda suelta a su imaginación pidiendo, por ejemplo, que pongan en su tumba una escultura de su perro, de una computadora, etcétera. Muchas veces la iniciativa proviene de los propios deudos, quienes supuestamente interpretan el sentir del difunto.

Otros, más bien, desean que se consigne sobre sus lápidas algunas frases, como Frank Sinatra, quien pidió que dejaran grabado en su tumba: "Lo mejor está por venir" (afirmación que habría que validar según hacia dónde termine yéndose uno después de muerto). Mas, como en todo en la vida, siempre hay que ser cautos con lo que se dice. En México, un viudo, con aparentes buenas intenciones, pero sin calcular sus alcances interpretativos, hizo poner la siguiente frase en la lápida bajo la cual yacía su cónyuge: "Acá descansa mi querida esposa Brujilda", y añadió a renglón seguido un pedido a Dios: "Recíbela con la misma alegría con la que yo te la mando".

La imaginación se desborda a veces ya no en el nicho o la tumba de los difuntos, sino en el velatorio. Así, en Puerto Rico, en el año 2010, David Morales Colón, un aficionado a las motos de 22 años de edad, pidió que lo velaran sentado sobre su motocicleta, y la familia - muy solícita - cumplió el encargo (el individuo, a quien llamaban el Matatán, había muerto aparentemente en un ajuste cuentas, acribillado por sicarios). Al velorio asistieron cientos de curiosos para tomarse fotos y videos con el difunto. La misma funeraria, ubicada en el barrio de Hato Rey, en el año 2008, había atendido el deseo de Ángel Luis "Pedrito" Pantojas Medina, otro joven también con antecedentes penales que fue asesinado y que había pedido que lo velaran de pie (Ferreira, 2010).

Posteriormente, en mayo del 2015, atendiendo también a su voluntad, el taxista puertorriqueño Víctor Pérez Cardona fue velado al volante del vehículo con el que se había ganado la vida durante los últimos quince años. Anteriormente, una mujer había sido velada en su 
mecedora, y un hombre con su ropa de boxeador parado sobre un cuadrilátero ("Taxista fallecido de cáncer fue velado al volante de su auto", 2015, párrs. 2 y 5). Se cuenta, además, que en octubre del 2005, también en Puerto Rico, un hombre en Río Piedras - Jomar Aguayo Collazo, quien murió en una masacre ocurrida en un negocio de la misma localidad de Hato Rey - fue velado sentado en una mesa de dominó del bar de su madre, vestido con ropa deportiva, lentes de sol $\mathrm{y}$, por supuesto, las fichas del juego de dominó.

Por su parte, el creador de las famosas papitas Pringles, Fredric J. Baur, fallecido el 4 de mayo del 2008 en Estados Unidos, pidió a sus hijos que cuando se muera lo incineren y que luego parte de sus restos sean puestos en un tubo del famoso snack. Sus deudos cumplieron escrupulosamente su voluntad y guardaron en ese envase parte de sus restos ("Pide creador de Pringles ser enterrado en un envase de papas", 2008). En el caso del creador de Doritos, que falleció en septiembre del 2011, este solicitó que cuando enterraran sus restos, en vez de tirar pétalos de flores, que lanzaran Doritos sobre su ataúd.

¿Tiene validez jurídica este tipo de deseos? Pensamos que cualquier decisión con relación al velatorio y entierro de una persona debe resolverse teniendo en cuenta, fundamentalmente, la voluntad de la persona, pero considerando a su vez el contexto de las costumbres, la cultura del lugar, el orden público y la moral social. Asimismo, si se trata de velatorios privados o cementerios privados, deben respetarse también las normas de estos. Así, por ejemplo, una iglesia puede oponerse válidamente a que en su local, al amparo del principio de autonomía de la voluntad, se vele al difunto de tal o cual manera que sea inapropiada de acuerdo con sus principios.

Otro caso curioso es el de una batalla legal ganada hace no mucho en Nueva York, que permitió que las cenizas de una mujer sean enterradas junto a su perro en un cementerio para mascotas. Al respecto, vistas con detenimiento las cosas, no parecería haber mayor objeción a que uno quiera enterrarse junto con su perro, en un cementerio para mascotas, mas muy diferente sería el caso inverso de una persona que quiera enterrar a su perro en un cementerio para humanos.

Finalmente, en cuanto al destino del cadáver, la pauta general es que, así como "el respeto por la memoria de los difuntos exige dar cierto lugar a su voluntad en cuanto al destino que tendrá su cadáver" (Morelli, 2009, p. 127), también se trata de respetar su integridad y su honorabilidad. 
Como señala Videla (1999): “A pesar de que muchos juristas consideran que es un hecho personalísimo disponer de la integridad personal, creo que también es un derecho humano personalísimo y familiar el respeto por la integridad del cuerpo fallecido de un ser amado" (p. 189).

\section{¿Pueden los cadáveres Ser objeto del derecho de propiedad?}

Una cuestión legal que se plantea es quién decide el destino del cadáver: ¿tienen los familiares la "propiedad" del mismo, como objeto que es? Al respecto, pueden encontrarse diversas posiciones:

Se trata de un derecho real de propiedad. Para Valencia Zea y Ortiz Monsalve (2004, p. 390), los herederos son propietarios del cadáver del causante, pero con un poder de disposición limitado; mencionan dentro de ello - citando a Enneccerus-Nipperdey- el hacerle un entierro adecuado, determinar el epitafio y excluir las intromisiones de los que no tienen derecho. Agregan que si ningún "heredero" reclama el cadáver, por una costumbre bastante universal, debe verse como una res nullius y, por eso, pueden aprovechar de él los institutos de investigación científica para estudios o experimentos. Valencia Zea y Ortiz Monsalve (2012) afirman que el cadáver puede considerarse como "cosa comercial, susceptible de apropiación, pero sometido a un régimen especial" (p. 14). Esta idea es repetida por Vásquez Ríos (1997, p. 208).

Más que estar ante un derecho real, jurídicamente estaríamos ante un derecho personal de los familiares, pues el cadáver no es ciertamente una cosa como un auto o una casa. Breccia, Bigliazzi Geri, Natoli y Busnelli (1995, p. 206) niegan tajantemente la posibilidad de hablar de un derecho de propiedad sobre el cadáver, pues este no tiene naturaleza y contenido patrimonial, y expresan, más bien, "intereses de índole exquisitamente espiritual".

Se trata de un derecho sui generis. Teniendo en cuenta el tipo de "objeto" del que hablamos, merece un tratamiento similar a lo que ocurre, por ejemplo, con los órganos humanos, tejidos como la sangre, o células como los espermatozoides, a los que se les da un tratamiento especial de acuerdo con su naturaleza.

En todo caso, parece prudente, como lo ha señalado la jurisprudencia argentina, que las disputas sobre la posesión de un cadáver se basen en los principios generales del derecho, más que en las normas sobre propiedad y posesión (Cámara en lo Civil, Sala F, 1969, citado por Morelli, 2009, p. 128). 


\section{¿Puede considerarse técnicamente como un robo LA SUSTRACCIÓN DE UN CADÁVER?}

Consideramos que estos casos no constituyen un atentado contra la propiedad, pues el cadáver no es objeto de propiedad privada, no tiene contenido patrimonial y está fuera del comercio. En todo caso, se estaría ante atentados contra la piedad, el respeto o la sepultura que merece. Sobre este particular, existen diversos pronunciamientos de la doctrina que pueden ser de utilidad para aclarar las dudas sobre la materia:

El cuerpo humano es inalienable; en vida o después de su muerte no puede ser objeto de un derecho patrimonial [...], el reconocimiento de la facultad de disponer del cadáver no implica la atribución de un derecho de propiedad. Evidentemente, el derecho de propiedad supone la posibilidad de alienar la cosa. (Monge Talavera, 2003, p. 134)

Pueden ser objeto del derecho de propiedad todas las cosas, corporales o incorporales, siempre que sean susceptibles de apropiación, presten una utilidad económica a su titular y estén determinadas. Ergo, el cadáver no puede ser objeto de propiedad. (Serrano Alonso y Serrano Gómez, 2005, p. 96)

El cadáver, en cuanto bien jurídicamente tutelado, no es objeto de propiedad privada. El cadáver se encuentra sujeto a las normas sanitarias de orden público y tiene el destino que la ley le señala: ser objeto de piedad y respeto, de sepultura, apto para trasplantes, experimentación y enseñanza, según el caso. Está fuera del comercio de los hombres. (Fernández Sessarego, 2007, p. 65)

Asimismo, autores como Rubio Correa (1995) niegan la posibilidad de hablar de un derecho de propiedad sobre el cadáver (p. 47). Criterio particular es el common law inglés, que no trata al cadáver como propiedad, sino como una res nullius. En cuanto al sistema estadounidense, puede decirse lo siguiente:

En Estados Unidos [...] los tribunales civiles de equidad siguieron el modelo judicial británico y dictaminaron que un cadáver no era, desde una perspectiva legal, propiedad del difunto o de sus descendientes. Mientras que los tribunales estatales en los siglos XIX y $\mathrm{xx}$ a veces comentaban que el estado legal de un cadáver era equivalente a un derecho de propiedad, la mayoría todavía se negaba a considerar un cadáver como una propiedad. (Cantor, 2010, p. 48)

Por su parte, Orgaz (1961), luego de señalar que el cadáver no es una cosa por no ser susceptible de tener valor patrimonial o económico, 
afirma que no caben sobre él derechos reales o personales, ya sea de los herederos, parientes o cualquier otra persona, por lo que no puede ser objeto de apropiación, robo o hurto, ni de un interdicto posesorio. Sin embargo, cuando por disposición de la persona o de las autoridades pertinentes puede ser entregado a un instituto con fines de estudio o enseñanza, en ese caso sí sería una cosa y puede ser objeto de actos jurídicos, siempre limitado por su destino, la moral y las buenas costumbres. Así, puede ser objeto de reivindicación o incluso de cesión o intercambio; entonces se habla de robo o hurto, si se cumplen los requisitos propios de estos delitos (pp. 135-136).

Como dice Cifuentes (1988): “Por naturaleza jurídica, los restos humanos son un bien material, pero no cosas susceptibles de valor. Luego, el cadáver está fuera del comercio" (p. 49). A su vez, Papaño, Kipeer, Dillon y Causse (2011) anotan que "el cadáver no es una cosa que pueda servir de soporte objetivo a un derecho real ni a una relación posesoria" (p. 10), aunque agregan seguidamente que, "sin embargo, atendiendo al uso médico o científico del cadáver o de partes de él, esta conclusión aparece algo atenuada $[\ldots] "$.

Una interesante sentencia sobre la disposición del cadáver, vinculada a un dramático y triste caso, es la expedida por el $26 .^{\circ}$ Juzgado Especializado en lo Penal de la Corte Superior de Lima, ante la decisión de EsSalud que se negaba a entregar a unos padres el cadáver de su hija recientemente abortada por causas naturales. La institución argumentaba que el cadáver no alcanzaba el peso establecido por una directiva interna de la Dirección de Salud (500 gramos) y, por lo tanto, no le podían entregar a la madre el cuerpo de su hija para darle sepultura. Al no tener las características suficientes para que sea considerada una persona, fue calificada como un aborto, situación en la cual no se podía emitir un certificado de defunción fetal. El juez resolvió reconociendo el derecho de los padres a sepultar el cadáver de la niña, pero para ello estos tuvieron que litigar durante dos años (Habeas Corpus 3189-2013, 2013).

Para Mosquera (2013), más allá del argumento de la libertad de culto alegado por la demandante, se trata de una vida humana que se extinguió y que, por tanto, más allá de su peso o tamaño, merece un tratamiento especial, que la distingue del que se da a las cosas, debiéndosele el mismo respeto y consideración que al cadáver de las personas (p. 15). Esta autora da cuenta de un caso similar ocurrido en Colombia (Expediente 3.687.534), en el que la Corte Constitucional de dicho país 
no solo reconoció el derecho de una madre de sepultar a sus dos fetos, sino que, además, dispuso que el municipio respectivo asuma el traslado de los cuerpos desde donde fue intervenida la madre hasta su lugar de residencia, por razones de solidaridad, ya que ella no disponía de los recursos necesarios (Mosquera, 2013, p. 15).

\section{Consideraciones finales}

Si bien la persona pierde con la muerte su condición de tal, no puede pensarse que se vuelve un simple objeto; su sola condición previa de persona exige determinadas consideraciones que merece su cadáver. Ello junto con el respeto que merecen las disposiciones de voluntad que pudiere haber expresado la persona en vida, teniendo en cuenta sus intereses y deseos. Debe reconocerse, como expresa Cantor (2010), una "autonomía prospectiva" que se proyecta después de la muerte.

En esencia, el interés de una persona en la autodeterminación se extiende a la organización previa de eventos que solo ocurrirán post mortem, un interés que yo llamo "autonomía prospectiva". Este interés de autonomía se reconoce en la venerable tradición de hacer cumplir los deseos premortem de una persona (como se expresa en un testamento) en la disposición post mortem de la propiedad de esa persona. (p. 29)

Más allá de aspectos técnicos, el cadáver del ser humano, sin duda, ni es una res nullius, ni es cualquier cosa, y merece, atendiendo a su naturaleza, una consideración especial, pues implica, de alguna u otra manera, una prolongación última de la personalidad, como señala Velásquez (1995, p. 4). Podemos hablar, entonces, de una personalidad pretérita que trasciende al fallecimiento de la persona misma, nos referimos a una personalidad pretérita trascendente.

Ahora bien, la definición del momento de la muerte es un asunto científico. El criterio más comúnmente aceptado es el de la muerte cerebral. Una vez definido ello, queda, sin embargo, en manos de la ciencia la delicada tarea de determinar ese momento específico, no pudiendo el derecho ser ajeno a los avances en ese conocimiento.

Fallecida la persona, sus restos no pueden ser usados para cualquier propósito, incluso aunque el propio difunto lo haya autorizado en vida. Por eso, sería inválido si una persona pide que su cuerpo, cuando muera, sea enterrado en un parque público, sea dado en alimento a los leones de un zoológico, se use de adorno en una discoteca, o se queme 
en una hoguera en la playa. Entra aquí a tallar el deber del respeto al orden público y las buenas costumbres. Cosa distinta es el caso de aquel ciudadano en Inglaterra que pidió que su cráneo, una vez muerto, sea utilizado en una representación de Hamlet de Shakespeare, voluntad que fue cumplida años después. El respeto a las disposiciones post mortem del difunto responde a la misma lógica que se aplica a las restricciones dejadas por el autor fallecido mientras la obra de su autoría no sea de dominio público.

En cuanto al estatus del cadáver, puede concluirse que este merece consideración, respeto, piedad, independientemente de que ya no sea persona. La burla o escarnio de un cadáver, hechos históricos como la exhibición de los cuerpos muertos de los hermanos Gutiérrez colgados en la Catedral de Lima en 1872, o noticias como el cortarle las piernas a un difunto para que quepa en un ataúd, constituyen agravios a la dignidad, ya que la muerte no convierte al cuerpo humano en un objeto. "Aunque el alma se haya separado del cuerpo, la dignidad de la persona se extiende más allá de la muerte y exige el debido respeto a lo que en vida constituyó una unidad con el alma" (González Pérez, 2011, p. 177).

Por ello, no puede verse al cadáver como un bien que forme parte de los derechos reales. Tiene una naturaleza sui generis, por lo que no cabe hablar de "propiedad" de los restos. No puede ejercerse sobre él un derecho de usar, de disfrutar y, solo en forma muy restringida, puede hablarse de un derecho a disponer.

Solo una visión "cosificada" y deshumanizadora del cadáver puede hacer que, para el derecho penal, sea más grave robarle un reloj a una difunta que tener acceso carnal a ella. En tal virtud, para una mejor regulación de la materia, resulta pertinente tener en cuenta lo establecido en el Código Penal Federal de México (cuyo artículo 281 dispone que se impondrá de uno a cinco años de prisión al que viole un túmulo, un sepulcro, una sepultura o féretro; y para el que profane un cadáver o restos humanos con actos de vilipendio, mutilación, brutalidad o necrofilia, si este último consiste en la realización del coito, la pena de prisión será de cuatro a ocho años) o en el Código Penal italiano (cuyo artículo 410 establece que cualquier persona que cometa actos de denigración sobre un cadáver o sus cenizas será sancionada con prisión de uno a tres años; si el infractor desfigura o mutila el cadáver, o comete sobre este acto de brutalidad u obscenidad, será castigado con prisión de tres a seis años). 
Cabe mencionar que, en el año 2012, se presentó en el Congreso de la República del Perú el Proyecto de Ley 1569/2012-CR, que proponía incorporar el artículo 318, literal B, en el capítulo I del Título XIV del Decreto Legislativo 635 (Código Penal), en los siguientes términos:

Artículo 318-B: Será reprimido con pena privativa de libertad no menor de 4 ni mayor de 8 años:

1. Al que profane un cadáver o restos humanos con actos de vilipendio, mutilación, brutalidad.

2. Al que ejerza sobre el cadáver actos de necrofilia consisten [sic] en la realización del coito.

3. Al que mutila o descuartiza un cadáver, o restos humanos con la finalidad de ocultar el delito y/o inutilizarlos como prueba.

La iniciativa parece interesante y debería ser objeto de revisión. Sin embargo, debe advertirse penosamente que, en la exposición de motivos del proyecto - presentado por el congresista Tomás Zamudio Briceño-, se citaron párrafos enteros de un autor mexicano: Héctor Villarreal (véase la referencia respectiva en la bibliografía del presente estudio), sin la más mínima mención de la fuente o entrecomillado. En todo caso, más allá de las normas jurídicas, nuestra capacidad para reconocer y respetar los derechos de quien no está ya para defenderse pone a prueba nuestra entereza, nuestra altura, nuestra integridad como personas; en suma, nuestra propia humanidad.

\section{REFERENCIAS}

Andorno, R. (2012). Bioética y dignidad de la persona (2. ${ }^{a}$ ed.). Madrid: Tecnos.

Aramini, M. (2007). Introducción a la bioética. Bogotá: San Pablo.

Arias-Schreiber Pezet, M. (1991). Luces y sombras del Código Civil (tomo I). Lima: Librería Studium.

Breccia, U., Bigliazzi Geri, L., Natoli, U., y Busnelli, F. D. (1995). Derecho civil. Normas, sujetos y relación jurídica (tomo I, volumen I). Bogotá: Universidad Externado de Colombia.

Cantor, N. L. (2010). After we die: The life and times of the human cadaver. Washington D. C.: Georgetown University Press.

Cifuentes, S. (1988). Elementos de derecho civil. Parte general. Buenos Aires: Astrea. 
Critchley, S. (2009). El libro de los filósofos muertos. México D. F.: Santillana Ediciones Generales, Taurus.

Doval, G. (2013). El libro de los hechos insólitos. Madrid: Alianza Editorial.

Espinoza, J. (2012). Derecho de las personas. Tomo I: Concebido y personas naturales (6. ${ }^{\mathrm{a}}$ ed.). Lima: Grijley.

Fernández Sessarego, C. (2007). Derecho de las personas. Exposición de motivos y comentarios al Libro Primero del Código Civil (10. ${ }^{\mathrm{a}}$ ed.). Lima: Grijley.

Ferreira, R. (28 de abril del 2010). En Puerto Rico velan a un muerto sentado en una motocicleta. El Mundo. Recuperado de https:// www.elmundo.es/america/2010/04/29/noticias/1272498158.html

Fonti, D. (2004). Morir en la era de la técnica. Córdoba: Ediciones de la Universidad Católica de Córdoba.

Gómez-Lobo, A. (2015). Calidad de vida y nutrición asistida. En F. León Correa (Ed.), Bioética desde los bienes humanos básicos. Homenaje a Alfonso Gómez-Lobo. Santiago de Chile: Fundación Interamericana Ciencia y Vida; Universidad Central.

González Pérez, J. (2011). La dignidad de la persona. Pamplona: Civitas-Thomson Reuters.

Jódar, F. (2015). ¿Pero está muerto o qué? Muy Interesante. Recuperado de http://www.muyinteresante.es/revista-muy/noticias-muy/articulo/pero-esta-muerto-o-que-231448620130

Lacruz Berdejo, J. L., Sancho Rebullida, F. de A., Luna Serrano, A., Delgado Echevarría, J., Rivero Hernández, F., y Rams Albesa, J. (2010). Elementos de derecho civil. Parte general. Madrid: Dykinson.

Laureys, S. (2005). Death, unconsciousness and the brain. Nature Reviews Neuroscience, 6(11), 809-909.

León Barandiarán, J. (1980). Curso elemental de derecho civil peruano. Lima: Gráfica Morsom.

Lete del Río, J. M. (1996). Derecho de la persona (3. ${ }^{a}$ ed.). Madrid: Dykinson.

Limongi Franca, R. (1995). El concepto de muerte ante el derecho al trasplante y el derecho hereditario. En VV. AA., Código Civil peruano. Diez años. Balance y perspectivas. Lima: Universidad de Lima. 
Llevadot, L. (2011). La muerte del otro: Kierkegaard, Lévinas, Derrida. Convivium, 24, 103-188.

López, M., y Abellán, J. C. (2009). Los códigos de la vida. Madrid: Homolegens.

Lorenzetti, R. L. (Dir.) (2014). Código Civil y Comercial de la Nación comentado (tomo I). Santa Fe: Rubinzal Culzoni Editores.

Lyon Puelma, A. (2007). Personas naturales (3. ${ }^{\text {a }}$ edición ampliada). Santiago de Chile: Ediciones Universidad Católica de Chile.

Monge Talavera, L. (2003). Comentario al artículo 8 del Código Civil. En VV. AA., Código Civil comentado por los 100 mejores especialistas. Lima: Gaceta Jurídica.

Morales Godo, J. (1997). Hacia una concepción jurídica unitaria de la muerte. Lima: Pontificia Universidad Católica del Perú, Fondo Editorial.

Morelli, M. G. (2009). Extracción de órganos de cadáveres con fines de trasplante. Voluntariedad y consentimiento presunto. Vida y Ética, 10(2). Recuperado de http://bibliotecadigital.uca.edu.ar/repositorio/revistas/extracción-órganos-cadaveres-consentimiento -presunto.pdf

Mosquera, C. (2013). Derecho de la madre a sepultar a su feto. Actualidad Jurídica, 239. Recuperado de https://www.researchgate.net/ profile/Enrique_Varsi-Rospigliosi/publication/322011504_Tratado_de_derecho_de_las_personas/links/5a3d51dfa6fdcce 197ff7a25/Tratado-de-derecho-de-las-personas.pdf

Orgaz, A. (1961). Derecho civil argentino. Personas individuales (2. a edición revisada y ampliada). Córdoba: Ediciones Assandri.

Palmero, J. C. (2000). La muerte y el derecho civil. En VV. AA., Muerte digna. Córdoba: El Copista.

Papaño, R. J., Kiper, C. M., Dillon, G. A., y Causse, J. R. (2011). Manual de derechos reales. Buenos Aires: Astrea.

Pérez Gallardo, L. (2014). La gestación tras el diagnóstico neurológico de muerte: ¿gestación post mortem? Revista Anales de la Facultad de Ciencias Jurídicas y Sociales, 44, 18-32.

Pide creador de Pringles ser enterrado en un envase de papas. (4 de junio del 2008). El Universal. Recuperado de http://archivo.eluniversal.com.mx/notas/512091.html 
Rodríguez Ramos, A. M. (2002). Implicancias éticas y jurídicas de la gestión post mortem: el "cadáver incubadora". En Familia, tecnología y derecho. Bogotá: Universidad Externado de Colombia.

Rubio Correa, M. (1995). El ser humano como persona natural. Lima: Pontificia Universidad Católica del Perú, Biblioteca Para Leer el Código Civil, vol. XII.

Serrano Alonso, E., y Serrano Gómez, E. (2005). Manual de derechos reales. Madrid: Edisofer.

Sgreccia, E. (2009). Manual de bioética. Tomo I: Fundamentos y ética biomédica. Madrid: Biblioteca de Autores Cristianos.

Taxista fallecido de cáncer fue velado al volante de su auto. (25 de mayo del 2015). El Comercio. Recuperado de https:/elcomercio.pe/mundo/ actualidad/taxista-fallecido-cancer-velado-volante-auto-191347

Valencia Zea, A., y Ortiz Monsalve, Á. (2012). Derecho civil. Tomo II: Derechos reales (11. ${ }^{\mathrm{a}}$ ed.). Bogotá: Nomos.

Vásquez Ríos, A. (1997). Derecho de las personas (tomo I). Lima: Editorial San Marcos.

Verdera Server, R. (2019). Lecciones de derecho civil. Derecho civil 1. Valencia: Tirant lo Blanch.

Vide, R. (1998). Derecho de la persona. Barcelona: J. M. Bosch.

Videla, M. (1999). Los derechos humanos en la bioética: nacer, vivir, enfermar y morir. Buenos Aires: Ad-Hoc.

Villarreal, H. (2013). Fundamentos de los derechos post mortem de la persona y su situación en la Ciudad de México. Recuperado de https://www.academia.edu/1131514/Fundamento_de_los_derechos_post_mortem_de_la_persona_y_su_situaci\%C3\%B3n_en_ la_Ciudad_de_M\%C3\%A9xico 